\title{
Ontogeny of synaptophysin and synaptoporin in the central nervous system: differential expression in striatal neurons and their afferents during development
}

\author{
W. Ovtscharoff ${ }^{\mathrm{a} . *}$, M. Bergmann ${ }^{\text {b }}$, B. Marquèze-Pouey c, P. Knaus c , H. Betz ${ }^{\mathrm{d}}$, D. Grabs ${ }^{\text {b }}$, \\ I. Reisert ${ }^{\mathrm{a}}$ and M. Gratzl ${ }^{\mathrm{a}}$ \\ "Abteilung Anatomie und Zellbiologie, Unicersität Ulm, Ulm (FRG), "Institut für Anatomie, Humboldt-Unicersität Berlin. Berlin (FRG). ZMBBH. \\ Universität Heidelberg. Heidelberg (FRG) and "Abteilung für Neurochemie, Max.Planck-Institut für Hirnforschung. Frankfurt a.M. (FRG)
}

(Accepted 3 November 1992)

Key words: Striatum; Development; Synaptic vesicle protein: Immunocytochemistry; In situ hybridization; Rat

\begin{abstract}
The expression of the synaptic vesicle antigens synaptophysin (SY) and synaptoporin (SO) was studied in the rat striatum, which contains a nearly homogeneous population of GABAergic neurons. In situ hybridization revealed high levels of SY transcripts in the striatal anlage from embryonic day (E) 14 until birth. In contrast. SO hybridization signals were low. and no immunoreactive cell bodies were detected at these stages of development. At E 14, SY-immunoreactivity was restricted to perikarya. In later prenatal stages of development SY-immunoreactivity appeared in puncta (identified as terminals containing immunostained synaptic vesicles), fibers, thick fiber bundles and 'patches'. In postnatal and adult animals, perikarya of striatal neurons exhibited immunoreaction for SO; ultrastructurally SO antigen was found in the Golgi apparatus and in multivesicular bodies. SO-positive boutons were rare in the striatum. In the neuropil, numerous presynaptic terminals positive for SY were observed. Our data indicate that the expression of synaptic vesicle proteins in GABAergic neurons of the striatum is developmentally regulated. Whereas SY is prevalent during embryonic development, SO is the major synaptic vesicle antigen expressed postnatally by striatal neurons which project to the globus pallidus and the substantia nigra. In contrast synapses of striatal afferents (predominantly from cortex. thalamus and substantia nigra) contain SY.
\end{abstract}

\section{INTRODUCTION}

Synaptic vesicles are key organelles in the regulated release of neurotransmitters and other molecules from chemical synapses. The membrane of synaptic vesicles is characterized by specific proteins involved in transmitter uptake, exocytosis and membrane recycling ${ }^{8,25}$. These include two members of a putative channel protein super-family, synaptophysin $(\mathrm{SY})^{9.28}$ and synaptoporin $(\mathrm{SO})^{11}$. SY and SO display a high degree of sequence identity ${ }^{11}$ and may form gap junction-like channels during neurotransmitter release ${ }^{2.26}$.

Synaptophysin and synaptoporin transcripts are differentially distributed in the postnatal and adult rat central nervous system ${ }^{16}$. In the striatum, SO transcripts are more abundant than SY mRNA ${ }^{16}$. While neurons in most brain areas are highly heterogeneous with respect to transmitters, almost all striatal neurons are GABAergic ${ }^{10.17 .20 .24}$. These cells, which project to the globus pallidus and the substantia nigra, receive afferent input from the cortex and the thalamus, and midbrain dopaminergic neurons ${ }^{22}$. Striatal GABAergic neurons constitute an essential component of the basal ganglia and have been implicated in a wide range of kinetic functions ${ }^{3}$. Perturbations of striatal input systems are believed to represent etiological factors underlying several neurological diseases ${ }^{4}$. Thus, analysis of synaptic organelle development might shed light on the mechanisms of striatal dysfunction. Here we report on the spatial and temporal patterns of SY and SO expression during prenatal and postnatal development of the striatum and on the cellular and subcellular expression of these vesicle proteins in the adult, as revealed by in situ hybridization histochemistry and immunocytochemistry at light microscopical and ultrastructural levels.

\footnotetext{
Correspondence: M. Gratzl, Anatomie und Zell Biologie. Universitä Ulm, Albert-Einstein-Allee 11. W-790) Ulm, FRG. Fax: (49) (731) 502-3217.

* Present address: Institut für Anatomie. Histologie und Embriologie, Medizinische Universität, BG-1431 Sofia, Bulgaria.
} 


\section{MATERIALS AND METHODS}

\section{Animals}

Adult rats of both sexes and pregnant rats (Sprague-Dawley) were purchased from Charles River (Sulzfeld, FRG). Embryonic tissue was obtained from day 14 to day 21 (E 14-21, day of insemination = day $O)$. In addition, tissue was obtained from newborn $(P$ 0) and postnatal rats (P 3, P 5 and P 8). The animals were anesthetized with $4 \%$ chloralhydrate $(1 \mathrm{ml} / 100 \mathrm{~g}$ b.wt. $)$. Brains were removed and further processed as described below.

\section{In situ hybridization histochemistry}

Cryostat sections of embryonic rat brains were mounted on poly-L-lysine coated slides and fixed in $4 \%(\mathrm{w} / \mathrm{v})$ paraformaldehyde in PBS. In situ hybridization was performed as previously described ${ }^{16}$. Briefly, the 45-mer antisense oligonucleotide probes ASy1 (complementary to nucleotides $514-557$ of the rat synaptophysin $\mathrm{CDNA}^{14}$ ) and ASo1 (complementary to nucleotides 1135-1180) and ASo2 (complementary to nucleotides 922-965) specific for rat synaptoporin transcripts ${ }^{11}$ were used in all experiments. Probes were 3 'endlabeled to identical specific activities with $5^{\prime}-\left[\alpha \alpha^{-35} S\right]$ dATP $(1,200$ $\mathrm{Ci} / \mathrm{mmol}$, NEN) using terminal deoxynucleotidyl transferase (Gibco/BRL, Eggenstein, FRG) at a 30:1 molar ratio of dATP: oligonucleotide. Control hybridizations were performed in the presence of a fifty-fold excess of unlabelled oligonucleotide. Sections were dipped in Kodak NTB2 emulsion (diluted 1:1 with water), developed and stained with $0.1 \%(\mathrm{w} / \mathrm{v})$ thionin.

\section{Immunocytochemistry}

For light microscopic immunocytochemistry, brains were immersed in Bouin's fixative for $12 \mathrm{~h}$ and embedded in paraffin. Serial sections $(6 \mu \mathrm{m})$ were cut and mounted on gelatin-coated glass slides. For immunohistochemical detection of SY and SO, polyclonal rabbit antisera directed against rat synaptophysin ${ }^{9}$ (kindly provided by $R$. Jahn, New Haven) or synaptoporin ${ }^{11}$ were used. Preliminary studies had shown that antibody dilutions of $1: 1,000$ (SY) and $1: 200$ (SO) resulted in highly specific labeling signals. These dilutions were therefore used in all experiments reported here. Details of the immunocytochemical procedures have been described previously ${ }^{1,12}$. Antigen/antibody complexes were visualized by the avidin-biotinperoxidase complex $(\mathrm{ABC})$ technique ${ }^{6}$. Controls incubated with $2 \%$ $(\mathrm{v} / \mathrm{v})$ goat serum in PBS or with normal rabbit serum $(1: 1,000)$ were negative.

To obtain specimens for electron microscopy, pregnant or nonpregnant rats were anesthetized $(4 \% \mathrm{w} / \mathrm{v})$ chloral hydrate, $1 \mathrm{ml} / 100$ g b.wt.). Fetuses were removed by Cesarean section and perfused transcardially for 5-6 min with $2 \%(\mathrm{w} / \mathrm{v})$ paraformaldehyde, $3 \%$ $(\mathrm{v} / \mathrm{v})$ glutaraldehyde, $1 \%(\mathrm{w} / \mathrm{v})$ acrolein, $2.5 \%(\mathrm{v} / \mathrm{v})$ dimethyl sulfoxide $(\mathrm{v} / \mathrm{v}), 9 \mathrm{mM} \mathrm{CaCl}_{2}$ in $0.1 \mathrm{M}$ cacodylate buffer, $\mathrm{pH}$ 7.4. Adult rats were perfused through the ascending aorta with the same fixative for
15 min. Subsequently, brains were removed, posttixed in the same fixative at $4^{\circ} \mathrm{C}$ for 3-4 $\mathrm{h}$, and placed in PBS overnight. Coronal sections $(30 \mu \mathrm{m})$ of the forebrain were cut on a vibratome (Oxford Instruments) and processed for pre-embedding staining employing the $\mathrm{ABC}$ technique ${ }^{6}$. Briefly, after treatment in $5 \%(\mathrm{v} / \mathrm{v})$ goat serum the sections were incubated for $12 \mathrm{~h}$ at room temperature and for 24 $\mathrm{h}$ at $4^{\circ} \mathrm{C}$ with anti-SY $(1: 1,000)$ or anti-SO $(1: 200)$, respectively. Biotinylated goat anti-rabbit IgG ( $1: 250$ dilution, $1 \mathrm{~h})$ and avidinbiotin-peroxidase complex $(1: 200$ dilution, $2 \mathrm{~h}$, Vector, Camon, Wiesbaden, FRG) were used in the second and third steps of immunostaining. All incubations were carried out at room temperature under gentle shaking. The peroxidase substrate consisted of $0.05 \% 3,3^{\prime}$-diaminobenzidine-tetrahydrochloride (Aldrich, Steinheim, FRG). After washing in $50 \mathrm{mM}$ Tris- $\mathrm{HCl}, \mathrm{pH} 7.6$, some sections were coverslipped for light microscopical observations. From other sections the striatal anlage was dissected, postfixed in $1 \%$ ( $w / v) \mathrm{OsO}_{4}$ in $0.1 \mathrm{M}$ phosphate buffer, $\mathrm{pH} 7.2$, for $45 \mathrm{~min}$, rapidly dehydrated and embedded in Epon 812 (Fluka, Neu-Ulm, FRG). For polymerization sections were placed between coverslips and slides precoated with dimethyldichlorosilane. Ultrathin sections were viewed unstained or poststained with lead citrate and uranyl acetate. Controls were carried out as described above.

\section{RESULTS}

First, SY and SO transcript levels were analyzed during prenatal development. At days E 14 and E 19 strong hybridization signals for SY mRNA were observed over the cells of the striatum (Fig. 1A and 2A,B). In contrast, SO mRNA signals were low at E 14 (Fig. 1B) and all later prenatal stages (data not shown). Apparently only the SY gene is efficiently transcribed in the prenatal striatum, whereas paucity of SO transcription is obvious in prenatal striatal neurons.

These data are supported by immunocytochemical observations, which revealed that numerous cells in the E 14 striatal anlage were intensely stained for SY whereas others showed moderate or weak reactions (Fig. 3A). SY-immunolabeling was found in cap-like arrangements around cell nuclei (Fig. 3B). Outside the perikarya no SY immunoreactivity was observed at $\mathrm{E}$ 14.

In contrast, at $\mathrm{E} 17$ and at later stages perikaryal SY immunolabeling was absent (Fig. 4A,C and D). How-
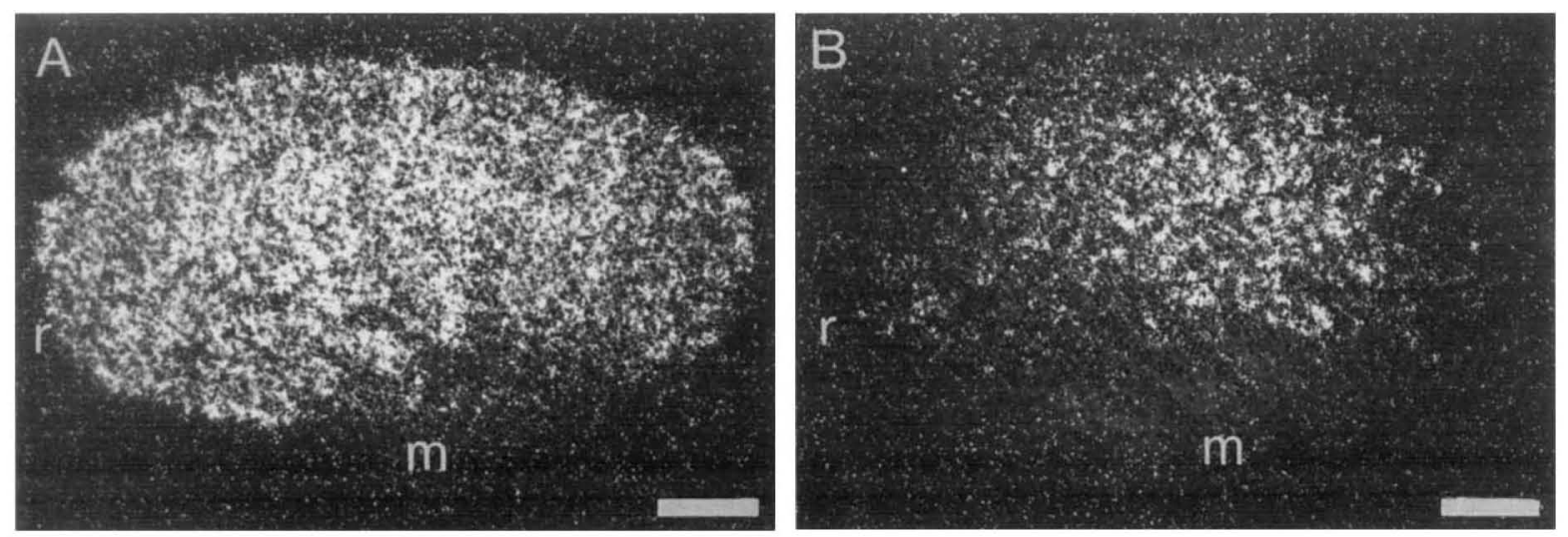

Fig. 1. Visualization of SY and SO transcripts in the striatal anlage at E 14. In situ hybridization histochemistry revealed a strong signal for SY (A) and a low one for SO transcripts (B). Horizontal sections. Dark field. Bar $=200 \mu \mathrm{m}$. m, medial; r, rostral. 

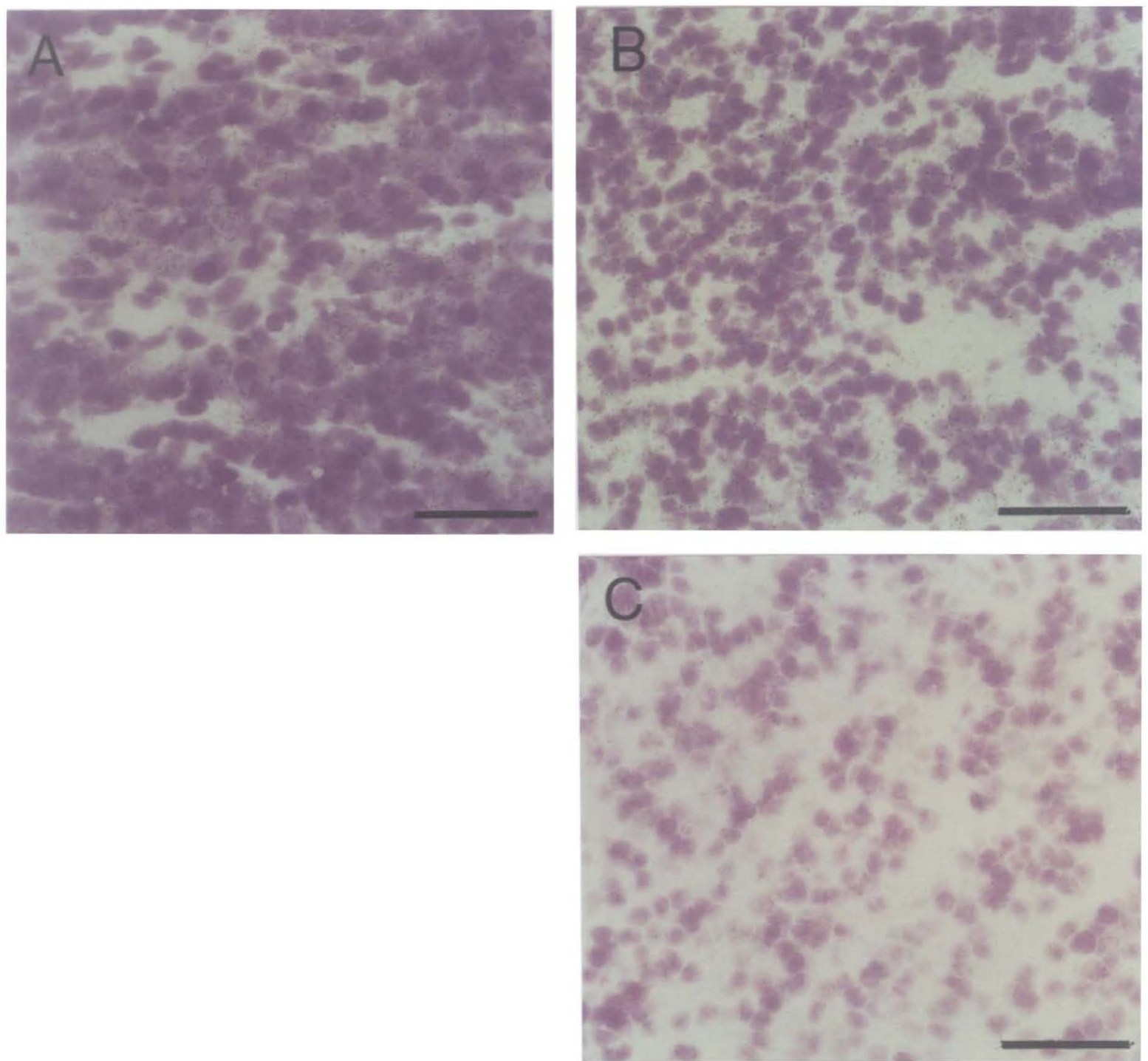

Fig. 2. Visualization of SY transcripts in striatal cell bodies at E 14 and E 19. High levels of SY transcripts are evident over cell bodies of striatal neurons at E 14 (A, same section shown also in Fig. 1A) and E 19 (B). No signal was detected over striatal neurons if a fifty-fold excess of unlabelled SY oligonucleotide was used (C). Bars $=50 \mu \mathrm{m}$.
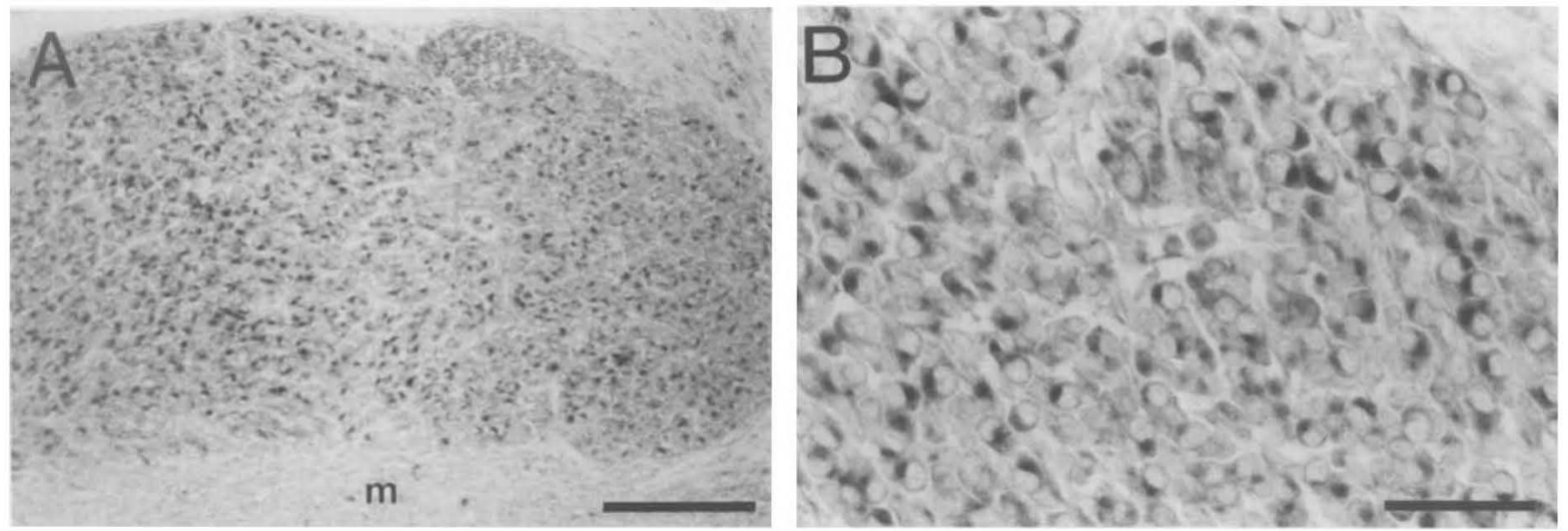

Fig. 3. Immunocytochemical detection of SY in the striatal anlage at E 14 Numerous SY immunoreactive perikarya were found (A). At higher magnification (B), a cap-like arrangement of the reaction product, closely associated with the nucleus, was observed. These structures may represent reservoirs of synaptic vesicles. Horizontal section. $\mathrm{Bar}$ in $\mathrm{A}=200 \mu \mathrm{m}$, in $\mathrm{B}=30 \mu \mathrm{m}$. m, medial. 

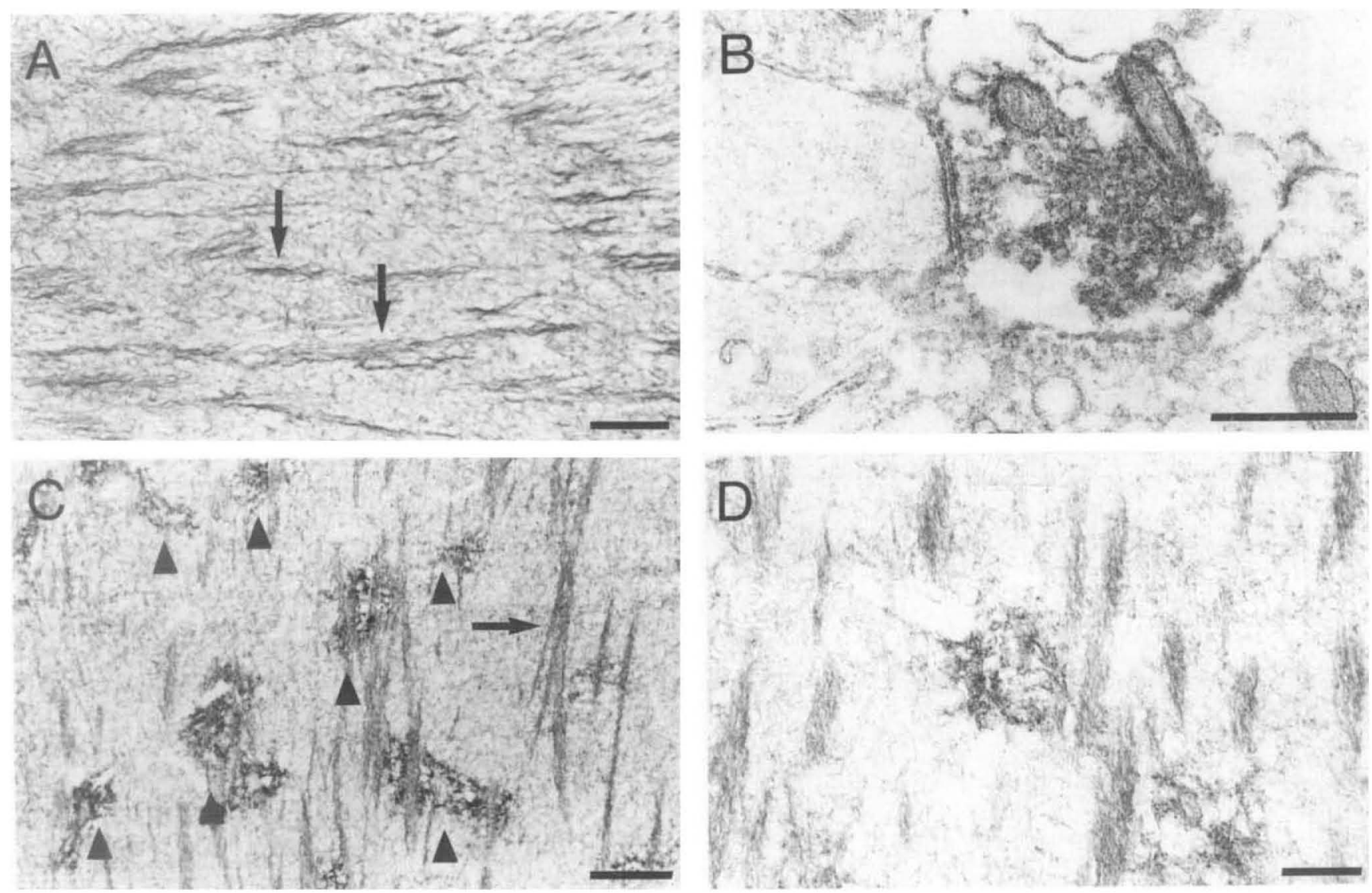

Fig. 4. Immunocytochemical detection of SY in the striatum at E 17, E 20 and P 0 . A: at E 17, immunostaining for SY was evident in puncta and in numerous fiber bundles (arrows). Note that no patches were seen in this developmental stage. B: terminals containing synaptic vesicles immunostained for SY were observed in the late prenatal period (E 20). C: at P 0, strong immunostaining for SY in fiber bundles (arrow) and numerous 'patches' (arrowheads) was found. $\mathrm{D}$; at higher magnification, a punctuate staining is revealed within the patches. Scale bar in $\mathrm{A}=25$ $\mu \mathrm{m}$. in $\mathrm{B}=0.5 \mu \mathrm{m}$, in $\mathrm{C}=40 \mu \mathrm{m}$, in $\mathrm{D}=12.5 \mu \mathrm{m}$.

ever SY antigen was found in thin nerve fibers and puncta. In addition, thick SY-immunoreactive axon bundles were conspicuous in the striatum at $\mathrm{E} 17$ and P 0 (Fig. 4A,C and D). Ultrastructural investigations revealed that the puncta of $S Y$ immunoreactivity within the striatum represent presynaptic endings (Fig. 4B). Moreover. at E 19 'patches' of SY-immunoreactivity

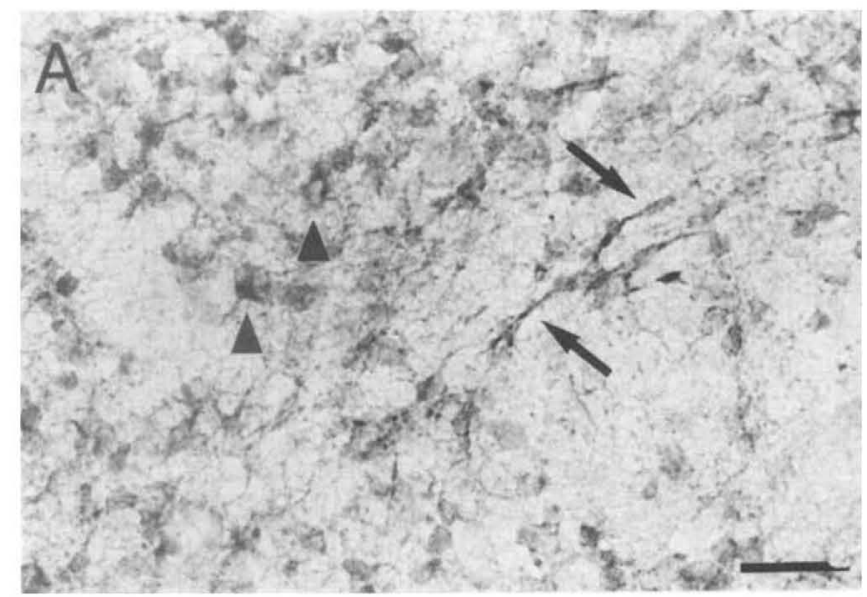

became evident. Their number increased between $\mathrm{E} 19$ and $\mathrm{P} O$. Numerous puncta, fibers, bundles and patches, intensely stained for SY, were found in the striatum at $\mathrm{P} 0$ (Fig. $4 \mathrm{C}$ and $\mathrm{D}$ ). No significant $\mathrm{SO}$ immunoreactivity was seen during the entire period of prenatal development.

Also within the first postnatal week the striatal

Fig. 5. SO immunoreactivity in striatal perikarya at P 3 and P 8 . Immunoreactivity is mainly confined to cell bodies (arrowheads) and fibers (arrows) A. P3. B: P8. Bars $=15 \mu \mathrm{m}$. 

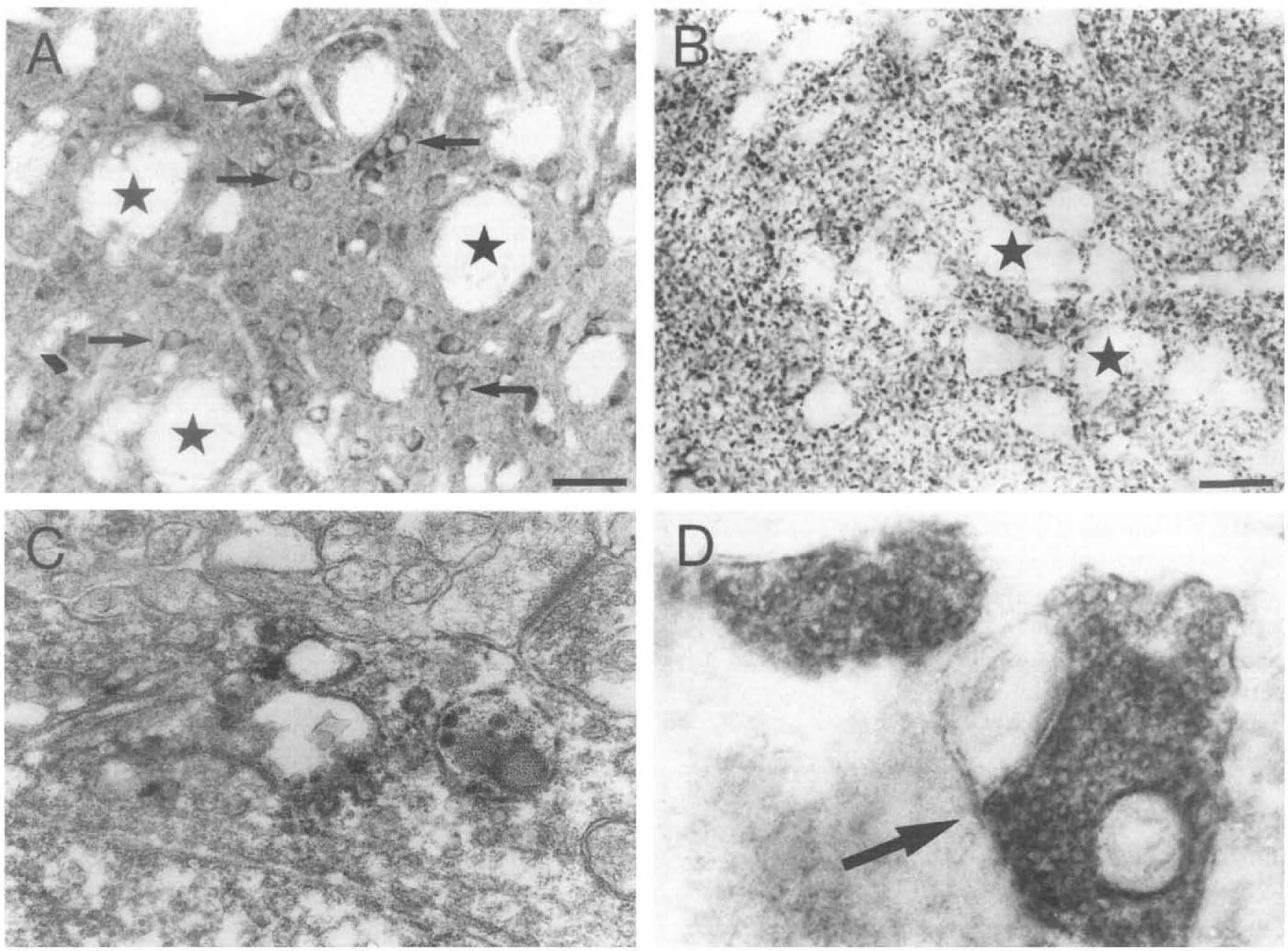

Fig. 6. SO and SY immunoreactivity in the adult striatum A: cross-sectioned axon bundles (stars) are unlabelled, whereas perikarya (arrows) show intense immunolabeling for SO. B: numerous SY-immunoreactive puncta were detected in the striatal neuropil. Unlabelled cross-sectioned thick internal capsule bundles are marked by stars. C: ultrastructural localization of SO immunoreactivity in the Golgi apparatus of a striatal neuron. Section poststained with lead citrate and uranylacetate. D: the SY-immunoreactive puncta (see C) correspond to nerve endings. Presynaptic terminals with SY-containing synaptic vesicles are shown. The arrow points to an (axospinous) synapse. No poststaining. Bars in $\mathrm{A}$ and $(\mathrm{C}=20$ $\mu \mathrm{m}$, in $\mathrm{B}$ and $\mathrm{D}=0.5 \mu \mathrm{m}$.

neuropil was heavily immunostained for SY. In contrast, SO immunoreactivity was mainly confined to the perikarya of striatal neurons (Fig. 5). In addition, immunoreactivity was found in some puncta and processes.

In the adult striatum numerous SY immunoreactive puncta (Fig. 6B) were revealed in the neuropil which were identified as presynaptic endings at the ultrastructural level (Fig. 6D). Compared to the situation seen around birth (see above) no SY immunoreactivity was seen in fibers. Also the internal capsule axon bundles respresenting corticofugal fibers exhibit no SY immunoreactivity (Fig. 6B). Immunoreactivity for SO was observed mainly in neuronal cell bodies (Fig. 6A). Ultrastructurally, immunoreaction product was found in the Golgi apparatus (Fig. 6C) and in multivesicular bodies (not shown). Only a few presynaptic boutons, immunoreactive for SO, were detected in the striatum (not shown).

\section{DISCUSSION}

The striatum is composed of a large fraction (approximately $95 \%$ ) of medium-sized spiny projection neurons and a small number of interneurons ${ }^{5.22 .29}$. Essentially all of the former and many of the latter are GABAergic ${ }^{10,17,29}$. Thus, signals to brain areas receiving striatal input, e.g. pallidum and substantia nigra, are predominantly conveyed via the inhibitory amino acid GABA. Striatal afferents are also well characterized and comprise mainly glutaminergic cortical and thalamic as well as dopaminergic inputs from the substantia nigra $4.210,22$.

The homogeneity of the striatal neuron population and the well documented striatal afferents provide an ideal basis to address pertinent questions regarding correlations between the biosynthesis of characteristic synaptic vesicle membrane proteins, fiber outgrowth and synaptogenesis. In addition, the adult striatum is 
one of the rare brain areas where SO transcripts are more abundant than SY transcripts whereas neurons projecting to the striatum (from the cortex, the thalamus and the substantia nigra) are rich in SY transcripts $^{16}$. Data describing SO and SY protein expression during prenatal development of the striatum and a comparison with that seen in the postnatal and adult rat therefore may help to elucidate basic mechanisms of basal ganglia development and function.

\section{Striatal neurons express mainly $S Y$ during prenatal devel- opment}

At E 14 a strong hybridization signal for SY mRNA, an intense perikaryal immunolabeling and the absence of immunopositive fibers imply that massive biosynthesis of SY takes place in the striatal anlage at this stage prior to striatal fiber outgrowth. Presumably, development of striatal neurons followed by fiber outgrowth, occurs between E 14 and E 17 when dopaminergic axons from the substantia nigra reach the striatum ${ }^{21,23}$. Also, expression of glutamic acid decarboxylase, enhanced under the influence of dopaminergic mesencephalic neurons, has been observed at this stage ${ }^{13,15,27}$. Taken together these data suggest that fiber outgrowth, expression of the synaptic vesicle antigen SY and GABA synthesis in striatal neurons are induced by dopaminergic afferents.

Around E 17 and E 19, the striatum receives ample synaptic input from the cerebral cortex ${ }^{24}$, but also from the thalamus ${ }^{7}$. The formation of these different inputs may be reflected by the strong SY immunoreactivity observed in fibers and thick striatal axon bundles followed by the formation of abundant synapses containing SY positive synaptic vesicles at E 20 . The presence of $\mathrm{SY}$ in outgrowing fibers prior to synaptogenesis has also been noted in the developing spinal cord'. In addition between $E 19$ and $P$, groups of neurons become surrounded by an intense network of SY-immunopositive structures. These 'patches' may correspond to 'dopamine islands' or 'striosomes', which represent ingrowing dopaminergic afferents from the substantia nigra ${ }^{4,19}$. In the developing cat striatum these 'patches' react with antisera against the synaptic vesicle protein synaptotagmin and tyrosine hydroxylase ${ }^{18}$.

$S O$ is the major synaptic vesicle antigen produced by postnatal and adult striatal neurons

Expression of SO mRNA was found to be low throughout the entire prenatal period, and no SO antigen could be detected immunocytochemically (this study). After birth, the signals of SO mRNA in the striatum increase dramatically ${ }^{16}$. We found that striatal neurons effectively accumulate SO protein at the same stage of development. Also, in the adult striatum both SO mRNA ${ }^{16}$ and SO protein (this study) are seen in most striatal neurons, which project to the globus pallidus and the substantia nigra. The few SO-positive boutons observed within the striatum may arise from local axon colaterals of striatal GABAergic neurons or corticostriatal projections. The latter interpretation is consistent with the presence of SO transcripts in the rat cortex ${ }^{16}$.

\section{SY persists in adult striatal afferents}

In the adult striatum, SY immunolabeling is restricted to nerve terminals but is absent in fibers. Since most synaptic endings in the adult contain SY immunoreactivity (this study), and since SY transcripts have been found in all brain areas projecting to the striatum $^{16}$, we conclude that SY is the predominant synaptic vesicle protein present in corticostriatal, nigrostriatal and thalamostriatal afferents.

Thus, synaptic inputs to the striatum differ from outputs with respect to the prevalent synaptic vesicle antigen. While striatal neurons produce $\mathrm{SO}$ as a major synaptic vesicle membrane protein, the terminals of striatal afferents contain SY. However, during prenatal development striatal neurons preferentially synthesize SY. This implies that around birth, striatal synaptic vesicles containing SY are replaced by vesicles containing SO. This may contribute to the stabilization and/or plasticity of the synaptic connection during the major phase of synaptogenesis in this brain region.

Acknowledgements. The authors thank Mrs. I. Urban, D. Wachenschwanz and R. Zienecker for expert technical assistence. W.O. was a visiting professor on leave from the Medical University of Sofia, Bulgaria. He was supported by grants from the Deutsche Forschungsgemeinschaft (UL-47/27-1) and the University of Ulm. This study was supported by Deutsche Forschungsgemeinschaft (Be 1330, Gr 681, Leibniz-Programm and SFB 317), by the Charité (Projekt 053 to M.B.), by EMBO (long-term fellowship to B.M.-P.) and Fonds der Chemischen Industrie.

\section{REFERENCES}

1 Bergmann, M., Lahr, G., Mayerhofer, A. and Gratzl, M., Expression of synaptophysin during the prenatal development of the rat spinal cord: correlation with basic differentiation processes of neurons, Neuroscience, 42 (1991) 569-582

2 Betz, H., Homology and analogy in transmembrane channel design: lessons from synaptic membrane proteins, Biochemistry, 29 (1990) 3591-3599

3 Goldman-Rakic, P.S. and Selemon, L.D., New frontiers in basal ganglia research, Trends Neurosci., 13 (1990) 241-244

4 Graybiel, A.M., Neurotransmitters and neuromodulators in the basal ganglia, Trends Neurosci., 13 (1990) 244-253

5 Heimer, L., Alheid, G.F. and Zaborszky, L., Basal ganglia. In G. Paxinos (Ed.), The Rat Nervous System, Vol. I. Forebrain and Midbrain, Academic Press, New York, 1985, 37-86.

6 Hsu, S.M., Raine, L. and Fanger, H., Use of avidin-biotin-peroxidase complex $(\mathrm{ABC})$ in immunoperoxidase techniques: a comparison between $A B C$ and unlabeled antibody $(P A P)$ procedures, J. Histochem. Cytochem., 29 (1981) 577-580 
7 Iñiguez, C., De Juan, J., Al-Majdalawi, A. and Gayoso, M.J., Postnatal development of striatal connections in the rat: a transport study with wheat germ agglutinin-horseradish peroxidase, Det. Brain. Res., 57 (1990) 43-53

$8 \mathrm{Jahn}, \mathrm{R}$. and De Camilli, P., Membrane proteins of synaptic vesicles: markers for neurons and neuroendocrine cells; tools for the study of neurosecretion. In M. Gratzl and K. Langley (Eds.). Markers for Neural and Endocrine Cells, VCH-VerlagsgeselIschaft, Weinheim, 1991, pp. 25-92.

9 Jahn, R., Schiebler, W., Ouimet, C. and Greengard. P., A 38,000-dalton membrane protein (p38) present in synaptic vesicles, Proc. Natl. Acad. Sci.USA, 82 (1985) 4137-4141

10 Kitd, H. and Kitai, S.T., Glutamate decarboxylase immunoreactive neurons in rat neostriatum: their morphological types and populations, Brain Res., 447 (1988) 346-352

11 Knaus, P., Marquèze-Pouey. B., Scherer, H. and Betz, H., Synaptoporin, a novel putative channel protein of synaptic vesicles. Neuron. 5 (1990) 453-462

12 Lahr, G., Heiss, C., Mayerhofer, A., Schilling, K., Parmer, R.J., O'Connor, D.T. and Gratzl, M., Chromogranin A in the olfactory system of the rat, Neuroscience, 39 (1990) 605-611

13 Lauder, J.M., Han, V.K.M., Henderson, P., Verdoorn, T. and Towle, A.C., Prenatal ontogeny of the GABAergic system in the rat brain: an immunocytochemical study. Neuroscience. 19 (1986) $465-49.3$

14 Leube, R.E., Kaiser, P., Seiter, A., Zimbelmann, R., Franke, W.W., Rehm, H., Knaus, P., Prior, H., Betz. H., Reinke, H., Beyreuther, K. and Wiedenmann, B., Synaptophysin: molecular organization and mRNA expression as determined from cloned cDNA, EMBO J., 6 (1987) 3261-3268

15 Lindefors, N., Brene, S., Herrera-Marschitz, M. and Persson, H. Region specific regulation of glutamic acid decarboxylase mRNA expression by dopamine neurons in rat brain. Exp. Brain Res., 77 (1989) $611-620$

16 Marquèze-Pouey, B., Wisden, W., Malosio, M.L. and Betz, H., Differential expression of synaptophysin and synaptosporin $\mathrm{mR}$ NAs in the postnatal rat central nervous system, J. Neurosci. 11 (1991) 3388-3397

17 Mugnaini. E. and Oertel, W.H., An atlas of the distribution of GABAergic neurons and terminals in the rat CNS as revealed by GAD immunocytochemistry. In A. Björklund and T. Hökfelt (Eds.). Handbook of Chemical Neuroanatomy, Vol. 4: GABA and Netropeptides in the CNS, Part I, Elsevier Science Publishers. Amsterdam, 1985, pp. 436-608.
18 Newman-Gage, $H$. and Graybiel, A.M. Expression of calcium/calmodulin-dependent protein kinase in relation to dopamine islands and synaptic maturation in the cat striatum. $J$. Neurosci., 8 (1988) 3360-3375

19 Olson, L., Seiger, A. and Fuxe, K.. Heterogeneity of striatal and limbic dopamine innervation: highly fluorescent istands in developing and adult rats. Brain Res., 44 (1972) 28.3-288

20) Reiner, A. and Anderson, K.D., The patterns of neurotransmitter and neuropeptide co-occurrence among striatal projection neurons: conclusions based on recent findings. Brain Res. Ret.. 15 (1990) 251-265

21 Reisert. I., Schuster, R., Zienecker, R. and Pilgrim, C., Prenatal development of mesencephalic and diencephalic dopaminergic systems in the male and female rat. Der. Bram. Res., 53 (1990) $222-229$

22 Smith. A.D. and Bolam. J.P., The neural network of basal ganglia as revealed by the study of synaptic connections of identified neurons, Trends Neurosci., 13 (1990) 259-265

23 Specht. L.A., Pickel. V.M., Joh. T.H. and Reis. D.J.. Light-microscopic immunocytochemical localization of tyresine hydroxylase in prenatal rat brain. I. Farly ontogeny, f. (omp. Neturol. 190 (1981) 233-253

24 Specht, L.A., Pickel, V.M., Joh, T.H. and Reis, D.J., Light-microscopic immunocytochemical localization of tyrosine hydroxylase in prenatal rat brain. II. Iate ontogeny. J. (comp. Netrol. 199) (1981) $255-276$

25 Südhof, T.C. and Jahn, R.. Proteins of synaptic vesicles involved in exocytosis and membrane recycling. Neuron. 6 (1991) 665-677

26 Thomas, L., Hartung. K., Langosch. D., Rehm, H., Bamberg. E., Franke. W.W. and Betz, H. Identification of synaptophysin as a hexameric channel protein of the synaptic vesicle membrane. Science, 242 (1988) 1050-1053

27 Vernier, P., Julien, J.-F.. Rataboul, P.. Fourrier. O.. Feverstein. C. and Mallet, J.. Similar time course changes in striatal levels of glutamic acid decarboxylase and proenkephalin mRNA following dopaminergic deafferentation in the rat. I. Neurochom. 51 (1988) $1375-1380$

28 Wiedenmann, B. and Franke. W.W. ldentification and localizattion of synaptophysin, an integral membrane glycoprotein of $M$, $38,000)$ characteristic of presynaptic terminals, ('ell, +1 (1985) $1017-1028$.

29 Wilson. C.J., Basal ganglia. In G.M. Sheperd (Ed.), The Synuptic Organization of the Brain. 3 rd edn.. Oxford University Press. New York. 1990, pp. 279-316. 